\title{
Seri, Bant Üretimin Mobilya Tasarım - Üretim Sürecine Etkisi Ve Modüler Mobilya
}

\author{
Yaprak Özel $^{1 *}$, Berna Kayacan ${ }^{2}$ \\ 1 İstanbul Gelişim Üniversitesi, Güzel Sanatlar Fakültesi, İç Mimarlık Bölümü, İstanbul, Türkiye (ORCID: 0000-0002-6439-4817) \\ 2 İstanbul Ticaret Üniversitesi, Mimarlık ve Tasarım Fakültesi, İç Mimarlık ve Çevre Tasarımı Bölümü, İstanbul, Türkiye (ORCID: 0000-0003-0941-486X)
}

(Illk Geliş Tarihi 12 Nisan 2020 ve Kabul Tarihi 26 Haziran 2020)

(DOI: 10.31590/ejosat.742261)

\begin{abstract}
ATIF/REFERENCE: Özel, Y. \& Kayacan, B. (2020). Seri, Bant Üretimin Mobilya Tasarım - Üretim Sürecine Etkisi Ve Modüler Mobilya. Avrupa Bilim ve Teknoloji Dergisi, (19), 623-632.

\section{Öz}

Mobilyalar, günlük hayatın içinde mekân ile kullanıcının bağını sağlarken, gerek işlevsel olarak gerek estetik olarak vazgeçilmez bir unsur oluşturmaktadır. İlk mobilya üretimlerine bakıldığında sadece ihtiyacın giderilmesi için ilişilen bir öğe olarak görülmektedir. Değişen ihtiyaçlar geliştirilen malzeme kullanımları ile mobilya biçimlenmeye ve gelişmeye başlamıştır. Sonraki aşamada işinin ehli ustalarca tek tek elle uzun sürelerde üretilebilen ürünler olarak karşımıza çıkmaktadır. Bu aşamada mobilya Kralların, asillerin veya soyluların iç mekânlarında görülebilen nesilden nesile aktarılan bir çeşit zinet eşyası değerindedir. Toplumsal statü ve ekonomik gücün bir sembolü görevindedir. Sahip olan kişiler bile çoğunlukla kullanmak yerine sergilemeyi tercih ettikleri görülmektedir.

Mobilya tasarım ve üretim süreci, sadece belirli kesimlerin kullanımına hitap edebilecek bir olgu olmaktan sanayi devrimi ve seri bant üretimi ile çıkmış herkese her kesime ulaşabilir birer ürün haline gelmiştir. Sanayi devrimi sürecinde gelişen buhar gücü ve fabrikalar ile ortaya çıkan seri bant üretim sistemi, birçok alandaki üretim yöntemlerini etkilediği gibi, o güne kadar yalnızca el işçiliği ile üretilen mobilyaların üretim şeklini de etkilemiştir. Bu üretim yöntemi ile modüler ve çoklu üretim metotları geliştirilmiştir. Yeni yönteme uygun tasarımlar yapılması gerekliliği ortaya çıkmış dolayısıyla da yeni ürünlerin hem kalitesinde hem biçimlerinde farklılıklar yaratmıştır. Ayrıca bu yeni üretim yöntemine uygun yeni malzemelerde geliştirilmiştir. Üretim yöntemin bir diğer kazanımı ise standarat ürün üretilebilmesidir. Seri üretim sisteminin getirdiği standardizasyon hareketine paralel olarak kullanıcının daralmış ve sınırlı mekânındaki donatı beklentisi; modüler mobilya çözümlerinde buluşmuş esnek dönüşebilir çözümler olarak karşımıza çıkmıştır. Bu makalede; tarihsel süreç içinde seri- bant üretim yöntemi, modül ve modüler mobilya kavramının oluşumu, modül kavramı, modüler sistemlerde tasarım prensipleri, modüler mobilya çözümlerinin iç mekana katkıları ele alınmaktadır.
\end{abstract}

\section{The Effect of Mass, Line Production on Furniture Design - Production Process and Modular Furniture}

\begin{abstract}
Providing the bond between space and user in daily life, furnitures form an irrevocable element both functional and aesthetical. Looking at the first furniture productions, they are seen as a component interfered with only to fulfill the needs. With changing needs and development of material uses, furnitures start to take shape and improve. The next phase they appear as time-taking hand made products produced by masterful experts. In this phase furniture is worth as ornaments passing down from generation to generation seen in spaces of kings, nobles and royals. It symbolizes social status and economical power. The owners prefer to display rather than to use.

The process of furniture design and production comes off from appealing to certain groups with industrial revolution and mass production line, and become a production that can be reached by all people. Effecting many production ways in many fields, steam power developed in industrial revolution process and mass production line also effected furniture production process, which are so far
\end{abstract}

\footnotetext{
* Sorumlu Yazar: İstanbul Gelişim Üniversitesi, Güzel Sanatlar Fakültesi, İç Mimarlık Bölümü, İstanbul, Türkiye, ORCID: 0000-0002-6439-4817, yaprakozel80@gmail.com
} 
produced only by manual labour. With this production method, methods of modular and mass production are developed. The necessity to improve new designs proper to new method emerged, thus created diversity in not only the quality, but also in form. Also new materials proper to this new production method are developed. Another gain of the new production method is producing standardized products. The user's expectation of equipment in narrowed and limited spaces parallel to standardized movement created by mass production system, meets in modular furniture solutions and comes up as flexible and transformable solutions. In this paper, mass - line production method, formation of modules and modular furniture concept, module concept, design principles in modular systems and contributions of modular furniture solutions to interior space are discussed in historical process.

Keywords: Product Design, Mass-Line Production, Interior Design, Modular Furniture, Manufacturing Technologies

\section{Giriş}

Mekânın hayata geçiren, tamamlayıcısı ve vazgeçilmez unsuru olan mobilyalar, teknolojiye ve farklılaşan iç mekân tercihlerine göre değişmekte ve gelişmektedir. Geçmişin emek-yoğun teknikleriyle üretilebilen, ancak belli kesimlere hitap edebilen, hiyerarşi ve lüks göstergesi gibi misyonlar taşıyan, standart olmayan, kalitesi ve üretim süresi ustanın el becerisine bağlı olarak değişkenlik gösteren mobilyalar, teknolojik gelişmeler ile çağın üretim koşullarına uyum sağlamıştır. Modüler mobilyanın doğuşu ile ilgili bir kaynakta şu şekilde belirtilmiştir; 20.yüzyılda giderek şehirleşen toplumda beliren yeni gereksinimlere yönelik mobilya endüstrileri 1.Dünya Savaşından önce ortaya çıkmaya başlamıştır. Şehre çalışmak üzere gelip tek başına yaşayan bekârlar için modüler mobilya sistemleri tasarlanmıştır (Boyla,2011). Savaş sonrasında ise; depolama elemanlarında kullanıcının gereksinim duydukça zaman içinde eklemeler yapabileceği standart modüler sistemlere gidilmiştir.

Sanayi devrimi ve endüstrileşme ile ortaya çıkan seri ve bant üretim sistemi sayesinde; mevcut malzemeler geliştirilmiş, yeni malzemeler keşfedilmiş, yeni üretim sistemine ve malzemelere uygun tasarımlar oluşturulmuştur

$\mathrm{Bu}$ yöntemler ve gelişmelerin arasında en önemli olanlardan bir diğeri ise standart ürün ortaya konulabilmesidir. Tipleştirmeler ve yasal olarak düzenlenmiş standartlar sonucu, el işçiliğiyle yapılan ürünlerde kişisel farklılıklara etki alanı bırakılmaktadır. Buna karşın, 20.yüzyılın sanayileşmiş normları ve yeni kalite anlayışı, tamamen aynı modelde büyük serilerin makineyle üretilmiş ürünler olmasını istemektedir.(Müller ve Vogel, 2012) Standartlaşmış üretimler ve seriler olarak üretebilme çıkan ürünün kalitesindeki yoksunluğu devre dışı bırakamasa da ürün çeşitliliği ve ihtiyaçların karşılanmasına sağladığı katkı tartışılamaz. Bu standartlar ürün kalitesini de kapsamına alması sayesinde yeni normlar, malzeme ve üretim teknikleri yeni tasarımları da içine alarak yükselişe geçmiştir.

Çalışma biçimi değişen toplumun, şehir yaşamındaki kalabalıklaşmaya bağlı olarak kullandığı iç mekânlarının da küçülmesi, dar alanlarda birden çok fonksiyonun yer alması gerekliliği ihtiyaç ve beklentileri gerek mekân kurgularında gerekse mekânların donattıkları mobilyaların da üretim ve biçimlenmesinde farklılık yaratmıştır. Bu bağlamda artan talebin karşılanması için hızlı, ekonomik şartların zorluğu nedeniyle üretim ve satış maliyetlerinin düşük olacağı üretimler yapılması gerekliliği doğmuştur.

Bu çalışmada seri bant üretimin tarihsel gelişimi mobilya tasarım ve üretim sürecine katkısı anlatılmıştır. Bu üretim yöntemi kullanılarak oluşturulan modüllerden meydana gelen mobilyalar ile seri, bant üretim yöntemi kullanılarak oluşturulan modüler tasarım konseptiyle üretilmiş mobilya kavramı anlatılmıştır. Modül kavramı tanıtılmış, modüler sistemin gelişimi ve avantajları sunulmuştur.

\section{Materyal ve Metot}

\section{1. Üretimin Tarihsel Gelişimi}

Sanayi devriminden öncesinde üretimler, konusunda tecrübeli ustalar tarafından atölyelerde tek tek uzun uğraşlar sonucunda ortaya çıkartılmaktaydı. Bu durum herhangi bir bozulma, kırılma yaşanması, tamir gerekliliği veya parça değişimi durumunda yine aynı ustaların müdahalesini gerektirmekteydi.

Seri, bant üretimin doğuş sürecine bakıldığında; “16.yy’ın başlarında Venedik Tersanesi’nde askeri gemilerin kanal boyunca belirli bir yolda ilerletilerek, önünde durduğu atölyelerde sırasıyla kurulumunun, donatımının yapılması; bir montaj hattı üzerinde üretimin gerçekleştirilmesinin ilk örneklerindendir. O dönemde, tecrübeli işçiler tarafından belirli bir standartta tek tek üretilen gemi parçaları, gerektiğginde değişimlerini sağlamak ve zamanı geldiğinde hızlı bir şekilde üretimi gerçekleştirmek amacıyla hazır tutulmuştur (Url-1)" .

İşletme düzeyindeki ilk standardizasyon hareketi ise, endüstri devriminden sonra olmuştur. 1793 y1lında ABD'li mucit ve sanayici Eli Whitney üretim ve tamirde yüksek tecrübe sahibi ustaların çalışması gerekliliğini değiştirecek bir yöntem geliştirmiş ve uygulamıştır. Amerikan ordusundan 10.000 adet tüfek siparişi alan Eli Whitney, her biri aynı parçalardan oluşan on adet silah üretmiştir. Parçalarını demonte şekilde karıştırdığı bu silahların montajını Amerikan kongre üyelerinin önünde hızlıca gerçekleştirmiştir. Geliştirdiği bu yöntem sayesinde, silahın bir parçası bozulduğunda, değiştirilmesi kolay, hızlı ve az maliyetli olmuştur. Böylece silah üretiminde usta olmayan kişilerin de çalışması mümkün kılınmıştır. Eli Whitney’in geliştirdiği yöntem ile üretim literatürüne yedek parça, parça değiştirme ve montaj gibi kavramlar girmiş, üretim firmaları daha az kalifiye işçilerle yüksek adetli, hızlı, uygun maliyetli, tamir ve parça değişimleri kolay yapılabilir üretimler gerçekleştirmeye başlamışlardır (Kayacan, 2017).

18.yy’da buhar gücünün mekanik üretimlerde kullanımı endüstri devrimini başlatmıştır. 20.yy da elektrik enerjisi ile çalışan makinelerin seri üretime girmesi ile de 2. dönemine girilmiştir. 1860'larda Chicago'daki et paketleme fabrikasında etlerin hareketli hat üzerinde ilerleyerek, bir işçiden diğerine ulaştırılması ile etin parçalarına ayrılarak paketlenmesinin, ilk hareketli üretim hattı örneği olduğu düşünülmektedir (McGovern ve Gupta, 2011). 
20.yy’a kadar yapılan üretimde süreç, akış ve standardizasyona yönelik denemeler modern üretim yöntemlerinde büyük bir devrime alt yapı oluşturmuştur. Et kesim yerlerinde elektrikli konveyöre asılı etlerin bir ray üzerinde ilerleyerek kesilmesi Henry Ford'a esin kaynağı olmuştur. 1913'te Highland Park Michigan'daki fabrikasında geliştirdiği hareketli montaj hattı ile seri üretimin öncüsü olmuştur. Henry Ford bu yöntem sayesinde "Model T" adlı tarihin en çok satan otomobillerinden birinin üretimini, önceden kurgulandığı parçaların sırasıyla birbirine monte edilmesi yöntemiyle birleştirme aşamalarını gerçekleştirmiştir (Kayacan, 2017 ).

"Fordizm" olarak bilinen bu kitlesel üretim yaklaşımı sayesinde, montaj süresi önemli ölçüde azaltılmış ve 1927 yllına kadar 15 milyon "Model T" otomobil monte edilmiştir (Fiell ve Fiell, 2011).

Fordizm, kitleler için insan ve makinanın beraber çalıştı̆ı bir sistemle belli bir koordinasyonda standart üretim yapmayı amaçlamıştır. $\mathrm{Bu}$ yöntem öncesinde, alanında tecrübeli işçilere ihtiyaç duyulurken, üretim sürecine montaj hattının dâhil olmasıyla düşük tecrübeli işçilere de çalışma imkânı doğmuştur (Kayacan,2017). Fordist üretimin avantajları düzgün bir akışla hızlı üretim yapabilmekken dezavantajı ürün çeşitliliğinin sağlanamaması idi. Ford tarafından üretilen "Model T" otomobili sadece siyah renkte ve 1926'ya kadar sadece bir çeşit gövde tipinde üretilebilmiştir.

Ford'un başarısı; tek tip ve kısa sürede, çok adet üreterek maliyeti düşürmesi ile daha geniş kitlelere ürün sunması sayesinde olmuştur. Bu üretim sisteminde esneklik; yani renk model gibi tüketicinin farklılık beklentileri karşılanamamıştır. Ford'un tek tip üretiminin karşısında rakip firma General Motors ise farklı bütçe ve isteklere sahip kullanıcı kitlesine ürün çeşitliliği ile karşılık vermiştir. Bu farkl1lık, General Motors'u Ford'un önüne geçirmiştir (Saydan,2004).

Seri üretim sistemi ile ortaya çıkan üretimler çeşitlilik gösterebilmektedir. Talebe ekonomi ve pazarlama yöntemlerine bağlı olarak bu ortaya çıan ürünler şu şekilde adlandırabilir:

- Tamamlanmış (Kullanıcı için hazır, montaj gerektirmeden yerine yerleştirilmeye hazır),

•Yarı Tamamlanmış (Kullanıcının tamamlaması gereken bazı küçük montajlar gerektiren),

- Ham malzemeden üretilmiş ( Kullanıcının kullanım tercihine göre renklendirilebilir)

•Sökülüp takılabilen (Tamamı kullanıcı tarafından monte edilmesini gerektiren, bir veya daha çok kullanııı montajına yardımcı olacak basit kılavuzlar içeren paketten oluşan)

- Sadece bağlantı veya ara parça gibi üretimler

Tek bir bant üzerinde önceden hazırlanmış parçaların monte edilmesi ile ürün üretimi; aynı üründen çok daha kısa bir sürede, aynı standartta, çok daha fazla sayıda ürün ortaya çıkartma imkânı sunmaktadır. Bir bant üzerinde devam eden seri üretim, ana kasanın hareketli bant üzerinde yürütülmesi ve gerekli adımlarda durdurularak gerekli parçaların belirlenmiş uygun yerlerine yerleştirilmesinden oluşmaktadır. Bu sürece işçilerin yanında gerekli noktalarda montaj robotları da destek verebilmektedir. Bu sayede çok daha kısa zamanda daha çok ürün ortaya çıkartılırken işgücü bakımından da tutumlu bir çözüm ortaya çıkmaktadır. Ayrıca sayısı az olan konusunda uzman ustaların yerine daha az bilgi sahibi işçiler de çalışma imkânı bulmakta bu da ihtiyaç duyulan iş gücünü ve artan nüfusun iş ihtiyacını karşılamaktadır. Kişiye özel, tek tek üretilen ürünlerin kalitesi ile seri üretimle üretilen ürünlerin kalitesi karşılaştırıldı̆̆ında tek üretimler her zaman üst bir değerde olsa da günümüz malzeme ve teknolojileri sayesinde bu fark azalmaktadır.

Mobilya tasarım ve üretim sürecinde de seri bant üretim tekniği çok etkin olmuştur. Bu tekniğe uygun malzemeler geliştirilmiş, yeni üretim tekniğine uygun tasarımlar oluşturulmuş ve organize çalışan fabrikalar tarafından gerekli ihtiyaç karşılamıştır. Modüler mobilyanın hayata geçmesindeki temel teknik seri üretimdir. Seri üretim bandı üzerinde aynı parçanın (modülün) tek bir seferde, belirli boyut ve formda, kolay ve emniyetli bir şekilde binlerce üretilebilmesini mümkün kılmaktadır. Tek bir parça bu şekilde üretilebildiği gibi bu parçaların birleştirilmesiyle oluşacak ürün de yine bu yöntemle üretilebilmektedir. Bu parçalar; boyanması, düzeltmelerinin ve kontrollerinin yapılması, montaja hazırlanması ve diğer parçalarla birleşmesi için yine bant sistemi üzerinde ilerlemektedir. Bandın son aşamasında son kontrol (satışa ve kullanıma hazır hale getirilme), ambalajlama ve nakil aşamaları yer almaktadır.

\subsection{Modül Tanımı Ve Modüler Sistemlerde Tasarım Prensipleri}

\subsubsection{Modül Tanımı}

Modül, kendi içerisinde yapısal veya fonksiyonel bütünlüğü olan birim, temel parça olarak tanımlanmaktadır. Modern Mimarlık'ta, standartlaşmayı büyük ölçüde kolaylaştıran, binanın ve bileşenlerinin ölçülerinde yinelenen bir uzunluk birimi olarak ifade edilir. (Hasol, 2010) Bir modülün, benzerleri ile birleştiğinde ya da tekrarlar ile çoğaltıldığında ölļü ve fonksiyon açısından farklı yapılar üretebilme özelliği vardır.

Yapı tasarımında; plan ve cephe kurgularında, mobilya tasarımında gelişebilen dönüşebilen ihtiyaca göre belirli bir oran orantıya göre farklılaşabilen çözümlemelerinde temel prensip olarak modül sisteminin kullanıldığı görülmektedir. Bir ana birim olarak belirlenen modül yanına eklenen parça ile bir oran orantı kurgusunda devam ederek istenilen bütün elde edilmeye çalışılır.

Örneğin: a ölçüsüne sahip bir modülün yanına gelen parça a/2 veya ax2 gibi ana modül ölçüsü ile bir oran orantıda düzenlenir. Bazen modülün bir ölçüsü sabit tutularak yanına kendisi kadar bir modül daha eklenerek bir yönde büyümesi sağlanır. Bu sayede a modül ve a modülünden üretilmiş bir yeni $\mathrm{b}(\mathrm{a}+\mathrm{a}=\mathrm{b})$ modülü meydana getirir. $\mathrm{Bu}$ bir sistem olarak tekrar edildiğinde ritmik bir düzenleme elde edilir. Modüler sistem ile oluşturulan kompozisyonlar kendiliğinden denge kurgusuna sahip olmaktadır. Böylece tasarım aşamasında, kompozisyonda denge kurgusunun geliştirilmesi için ek bir çaba gösterilmesi gerekmez. 
İç mekân ve yapının muhtemelen en erken ve en önemli modülü tatami matıdır. 14.yy’a ait Tatami proporsiyonu iç mimarlık ve mimarlığa ait kritik bir Japon ölçüsüdür. Tatami yalnızca iç mekânı tanımlamaz, ayrıca yapılı çevre proporsiyonu için de bir temel tȩ̧kil eder. Bina için yapısal modül olan ken, 2 tataminin boyutuna eşittir ve mobilya tatami matının 1/2'si ya da 1/4'ü ü olarak tatami proporsiyonundan çıkarılır (Schneiderman, 2011), (Şekil 1).

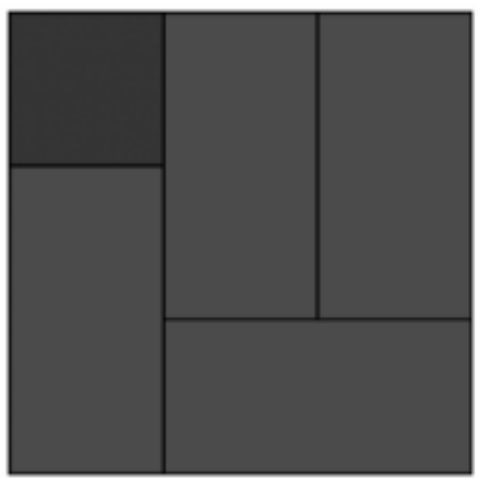

Şekil 1. Tatami Proporsiyonu (Schneiderman, 2011)

Modüler, modüle değin, belli bir ölçüye dayanarak oluşturulan, bir modüller bütününden oluşan tasarım olarak tanımlanmaktadır. (Hasol,2010) Modüler tasarım, ayrı ayrı tasarlanmış alt öğeler kullanarak çeşitli ürünler, eşyalar v.b. tasarlama disiplini olarak ifade edilmektedir.

\subsubsection{Seri Üretime Yönelik Modüler Sistemlerde Tasarım Prensibi}

Modüler sistemlerde tasarım prensibi, en basit birimlerin tasarlanması ve bu birimler ile olabildiğince geniş bir ihtiyaç yelpazesine cevap verebilmek esasına dayanmaktadır. Bu sistemde iki ana tasarım adımı bulunmaktadır.

Birinci tasarım adımında modülü oluşturan parçaların kendi başlarına bir anlam bütünlüğü oluşturmadığ 1 ancak bir araya geldiklerinde yani modülü oluşturduklarında bir anlam içerdiği tiptir. Modülü oluşturan parçalar seri, bant üretiminde a, b, c, d, gibi farklı parçalar olarak çok sayıda üretilirler. Bir araya getirilmek üzere bir bant üzerinde her biri gerekli yerlerine yerleştirilmesi suretiyle modüle ulaşılmaktadır. Parçalar tek başlarına bir mana ifade etmeseler de bir araya geldiklerinde bir biçim oluşturmaktadır. Ayrıca birer ara parça görevi görerek farklı bir modülün oluşturulmasında yedek parça olarak da kullanılabilirler. Bu parçalar çok sayıda birbirlerine eklenerek farklı bir birim oluşturmak için de kullanılabilir. Seri üretim ile ortaya çıkan her bir parça ancak montajdan sonra ana modülü oluşturabilmektedir. (Şekil 2)

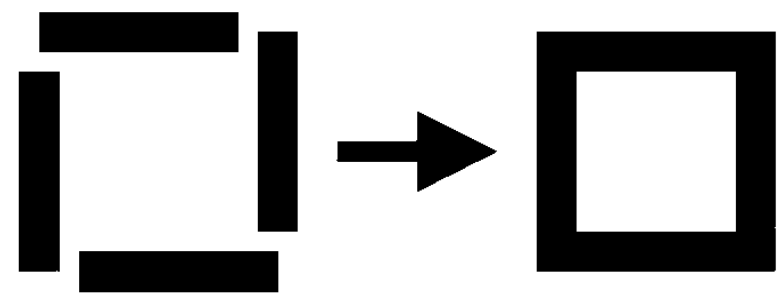

Şekil 2. Parçadan Modüle (Hadi, 2013)

İkinci tasarım adımında ise; en küçük birim olan modül bir parça görevindedir. Bu modül tekrar edilerek farklı çoklu kurgu/konfigürasyonlar oluşturulmaktadır. Bu sistemde ax2 veya a'nın tekrarları ve katları ile hem üretim hem tasarım açısından modülerlik oluşturulmaktadır. (Şekil 3).

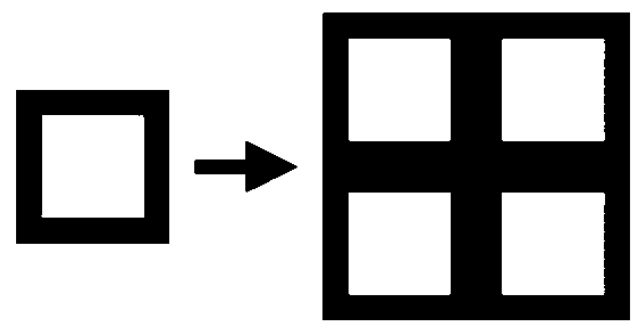

Şekil 3. Modülden Çoklu Kurguya (Hadi, 2013) 
Modüler sistemler seri üretilmektedir. Fakat her seri üretim ürünü, modüler kullanım için üretilmiştir denilemez.

\section{Araştırma Sonuçları ve Tartışma}

\subsection{Modüler Mobilya Sistemleri}

Modüler mobilya standart olmak zorundadır. Modüler mobilyada standart olma özellikleri kalitede, teknolojide, fiyatta, müşteri hizmetlerinde, dağıtım teşkilatında ve hepsinden önemlisi boyutta standardizasyon biçiminde tanımlanabilir. Bütün bu standardizasyonu sağlamak için fabrikasyon üretimi gerekmektedir. Yüksek teknoloji ve robotlu sistemlerin kullanıldığı fabrikalarda yapılan üretimlerle geniş kitlelere aynı fiyat ve kalitede ulaşabilme olanağı vardır.

Seri üretim bandı üzerinde aynı parçanın tek bir seferde binlerce üretilebilmesi ve bu parçaların bir araya gelerek oluşturduğu mobilyalar, modüler üretim sistemi ile üretilmiş mobilyalardır.

Modüler tasarlanmış mobilya ise, bir modülün yan yana veya üst üste tekrar edilerek yerleştirilmesi ile ünitelerin oluşturulduğu mobilya sistemidir.

\section{2. Özellikli Modüler Mobilya Örnekleri}

\subsection{Modüler Üretim Sistemi İle Üretilmiş Mobilyalar (1. Tasarım Adımı: Parçadan Modüle)}

Parçadan modüle üretim örneklerinden en iyi tanınanı ve öncüsü; Michael Thonet'in 214 no'lu sandalyesidir. 1800'lerin ortalarında, daha önce sadece el işçiliği ile yapılabilen sandalyelerin seri üretiminin yapılabilmesi için çalışmalara başlanmıştı. Michael Thonet'in tasarım tarihinde devrim niteliği taşıyan ahşap bükme yöntemi ve modüler sistemde üretimi icadı endüstriyel mobilya üretimi için önemli bir temel oluşturmuştur. 214 no'lu sandalye, tarihte işgücünün evrelere ayrılarak endüstrileştirildiği ilk mobilya örneğidir. Kutulanması ve modüler olarak parçalara ayırarak istiflenebilmesi sayesinde, 36 adet sandalyenin bir metreküp hacme sığabildiği ilk örnek olarak tarihe geçmiştir. Dünya çapında bu şekilde satışı ve sevkiyatı 1900'lü yılların başlarından beri yapılmaktadır. Küresel anlamda ticaretin ilk örnekleri arasına girmiştir. Michael Thonet'in 214 no'lu sandalyesi modern mobilya tarihinde bugüne kadar seri üretimde kalmış en başarılı ürün olarak bilinmektedir (Eroyan, 2012) (Şekil 4).

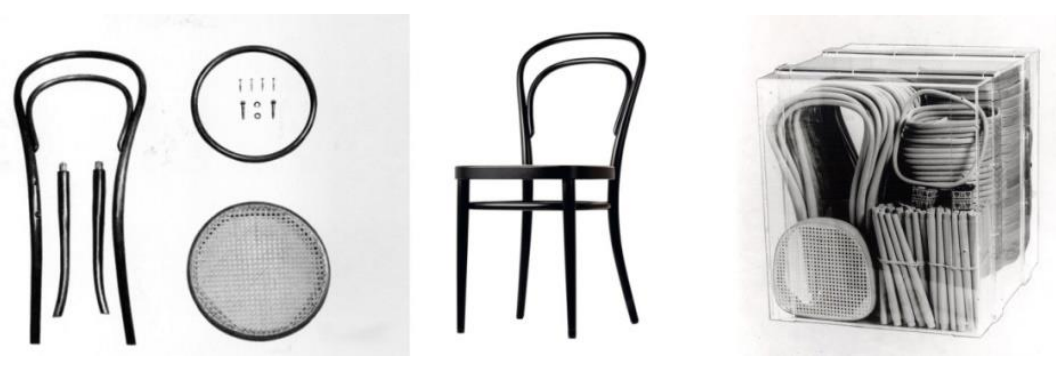

Şekil 4. Thonet Chair No:214, 1791 - 1871 (Url-2)

Güncel tasarımlardan bir örnek olarak; tasarımcı Stefan Diez’e ait Kitt sandalye incelendiğinde etkileyici görsel ve anlatı özelliklerine sahip güçlü bir endüstriyel mobilya tasarımı görülmektedir. Küçük bir kutu içinde temin edilen sandalye neredeyse hiç alet kullanmadan montajı yapılabilmektedir. Oturma yüzeyi kadar Geniş bir sırtlığa ve yuvarlak hatlara sahiptir. Oturma yüzeyi ve sırtlık cilalanmış kontrplaktan, bacakları masif ahşaptan üretilmiştir. Ayrıca, oturma yüzeyinin çevresi ahşaba benzeyen sağlam bir poliamidle çevrelenmiştir. (Şekil 5).
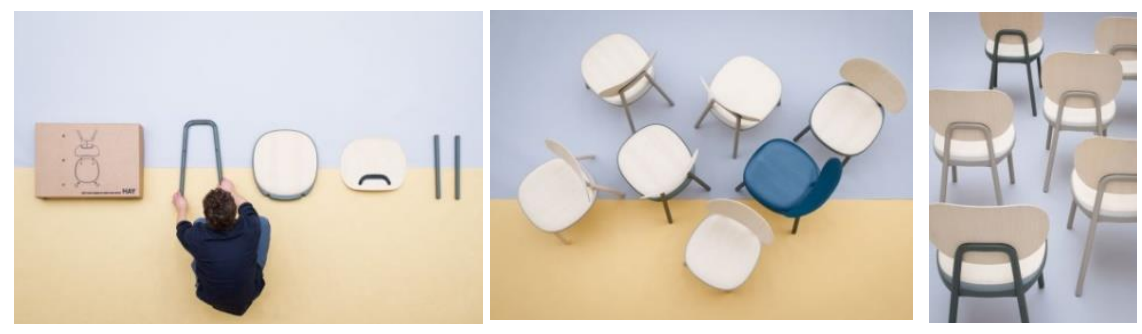

Şekil 5. Hay, Kitt Chair, Stefan Diez, (Url-3) 
Bir diğer örnek ise; İtalyan tasarımcı Giorgio Biscaro'nun bükülmüş kontrplaktan tasarladığı yassı bir kutu içine sığabilen tabure tasarımıdır. Milano'daki salone Satellite'da sergilemiştir. Offset isimli bu tabure tek parça kontraplaktan kesilen dilimlerin metal çubuklarla 3 bacaklı bir profil tarafindan tutturulmasıyla oluşturulmuştur(Şekil 6).
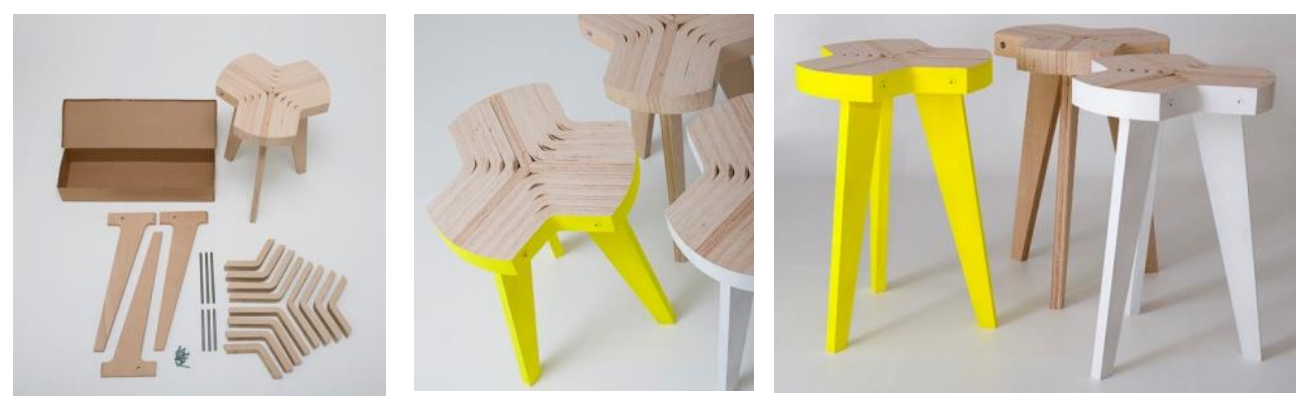

Şekil 6. Offset, Giorgio Biscaro Design Studio (Url-4)

\subsection{Modüler Üretim Sistemi İle Üretilmiş Ve Modüler Kullanıma Olanak Veren Mobilyalar (2. Tasarım Adımı: Modülden Çoklu Kurguya)}

Modülden çoklu figürasyona yöntemi ile yapılmış tasarımların örneklerinde: Eames depolama ünitesi, 1950-52 yıllarında Ray Kaiser Eames ve Charles Eames tarafından tasarlanmış ve Herman Miller Furniture Company tarafindan endüstriyel yöntemler kullanılarak üretilmiştir. ESU, Charles ve Ray Eames'in endüstriyel üretim materyalleri ve tekniklerini kullanarak ekonomik, ucuz ev mobilyaları yaratma çabasının bir parçası olarak tasarlanmıştır. Lake Masonit paneller, lamine huş kontrplak sürgülü kapaklar ve çekmeceler, delikli alüminyum paneller ve çinko kaplı çelik desteklerden oluşan hafif, modüler, istiflenebilir depolama üniteleridir. Bu sistemi tasarlarken, Eamesler ipuçlarını depolarda ve fabrikalarda bulunan metal raflardan aldı. ESU, standartlaştırılmış, seri olarak üretilen, sökülebilir, değiştirilebilir parçalardan oluşmaktadır: raflar, çekmeceler, paneller, kapaklar, metal çerçeve ve dikmeler. Parçalar sadece dayanıklı olmakla kalmayıp, aynı zamanda renkli paneller ve "çukurlu" kontrplak kapaklar ile delikli metal levhalar gibi dokulu yüzeyler kullanılarak dekoratif etki de yaratılmıştır. Mevcut renklerin ve yüzeylerin çeşitliliğ̈i, tüketicilerin ünitelerini ev ve ofis için özelleştirmelerini sağlamaktadır. Depolama üniteleri, oda bölücüleri olarak da kullanılmak üzere çeşitli boyutlarda tasarlanmıştır.(Şekil 7).
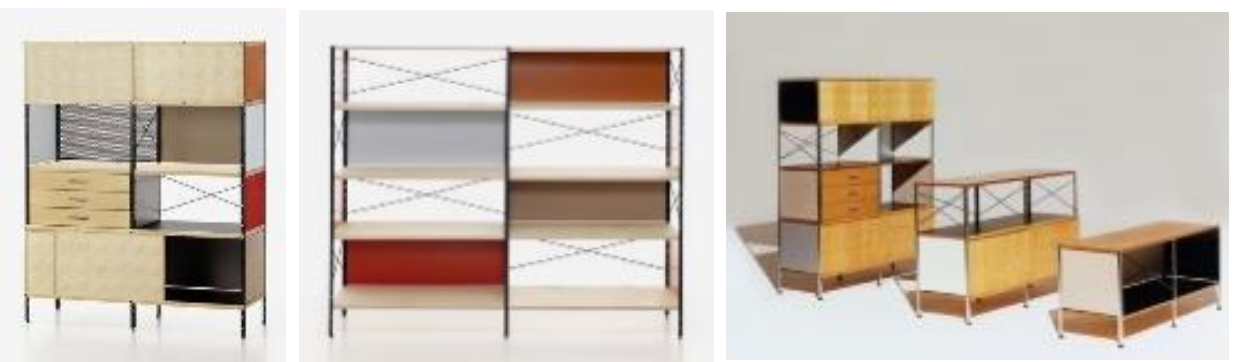

Şekil 7. Eames, Storage Unit 400 Series (Url-5)

1956'da George Nelson tarafindan tasarlanmıştır. Marshmallow koltuk geleneksel koltuk fikrini, 18 renkli minder ile sırtlık ve oturma fontunu basit çelik çerçeveye tutturmuştur. Alışa gelmiş koltuk fikrini eğlenceli 3 boyutlu bir objeye dönüştürmüştür. Bu farklılığı onu tasarım tarihindeki en sıra dışı koltuğu yapmaktadır. 6 ek minderli bir genişleme parçası, 2 sofa ünitesi arasına takılarak sınırsız uzunlukta olması sağlanabilmektedir. Her bir minder dayanıklı vinil ile kaplanmıştır. (Şekil 8).
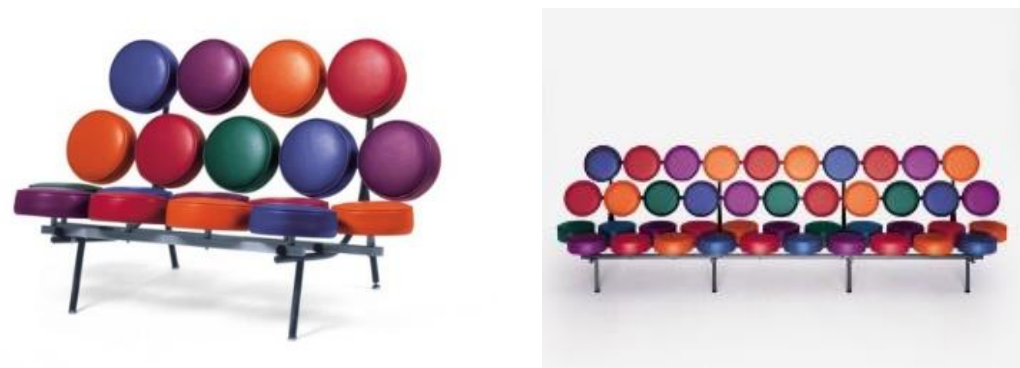

Şekil 8. George Nelson, Marshmallow Sofa, 1956 (Url-6) (Url-7) 
Bang \& Olufsen için 1959'da Danimarkalı tasarımcı Ib Fabiansenin Modüler Sistem Mobilya konseptli bir ürün tasarlamıştır. Bu sayede Televizyon ve ses cihazı tek mobilyada birleştirilmiştir. Fikir, basit bir sistemi satın alan kişinin zamanla ona ekleme yapabilmesidir. Çamın ve parlak renklerin kullanılması - o zamana göre sıradışı - meraklıların çok ilgisini çekmiştir. Maalesef çok az sayıda satılmıştır. Zamanına göre yaratıcı bir tasarım olan bu sistem 1958 Danimarka Sanat \& Zanaat Sergisi’nde sergilenmiş̧ir(Şekil 9).

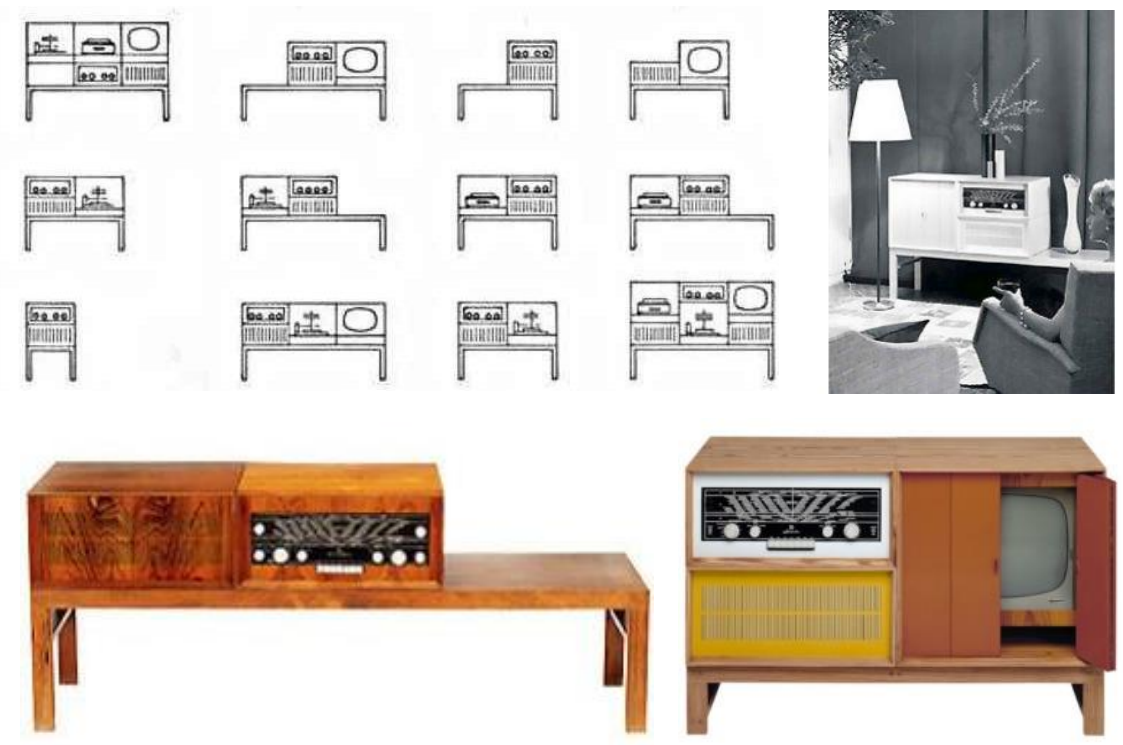

Şekil 9. IB Fabiansenin, Modular System, 1950 (Url-8)

Geleneksel Japon kâğıt katlama tekniklerinden esinlenen Amerikalı-Japon tasarımcı Isamu Noguchi, küçük prizmatik üçayaklı yan sehpayı siyah ve beyaz seçenekleri ile 1957 'de tasarlamıştır. Seri üretilen ilk mobilyasıdır. Katı, geometrik, net, minimalist ve basit bir tasarımdır. Vitra tasarım müzesi tarafından üretilmiştir(Şekil 10).
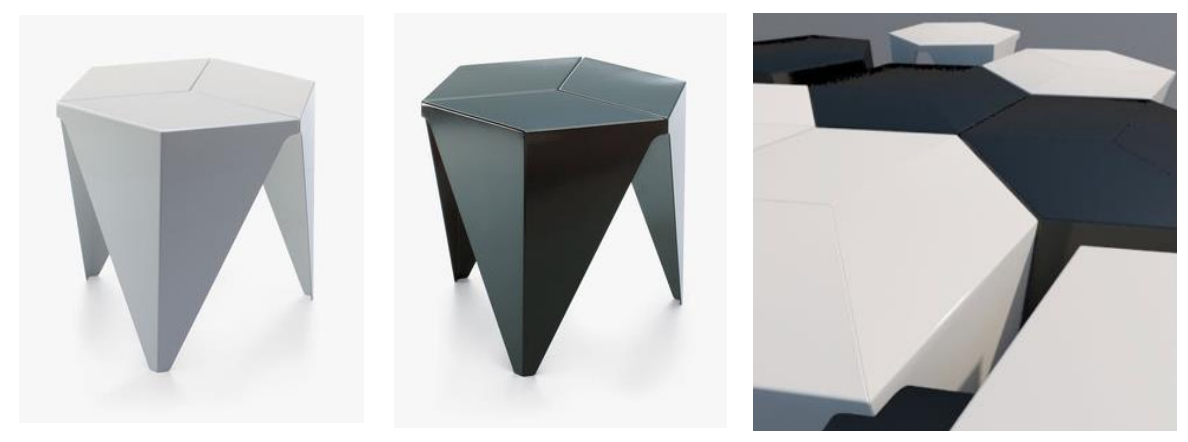

Şekil 10. Isami Naguchi, Prismatic Table, 1957 (Url-9) (Url-10)

Don Chadwick'in modüler oturma elemanı modüler sistemin, birkaç parçadan sonsuz çeşitlilik elde edilebileceğinin en iyi örneklerinden biridir. Beş basit, kalıplanmış yumuşak görünümlü birim, sistemin çok sayıda form almasını sağlar. Arkadaki derin cepler hava dolaşımını ve daha kolay temizlenmesini sağlamaktadır. Her parça çeşitli kumaşlardan üretilebilmekte, ön, arka ve yanları tamamen döşeme ile kaplı olduğu için bir uç, iç veya tek parça koltuk görevi görebilmektedir. Birimler basit konektörlerle güvenli bir şekilde birbirine bağlanabilmekte ve kolayca yeniden düzenleme için kilitler açılabilmektedir.1974'te tasarlanan koltuk günümüzde çağdaş koltuk yüksekliği ve güçlü taşıyıcı malzeme ile güncellenmiştir. Çok yönlü ve dayanıklı salon mobilyası seçeneklerinden biri olmaya devam etmektedir (Url-11). (Şekil 11). 

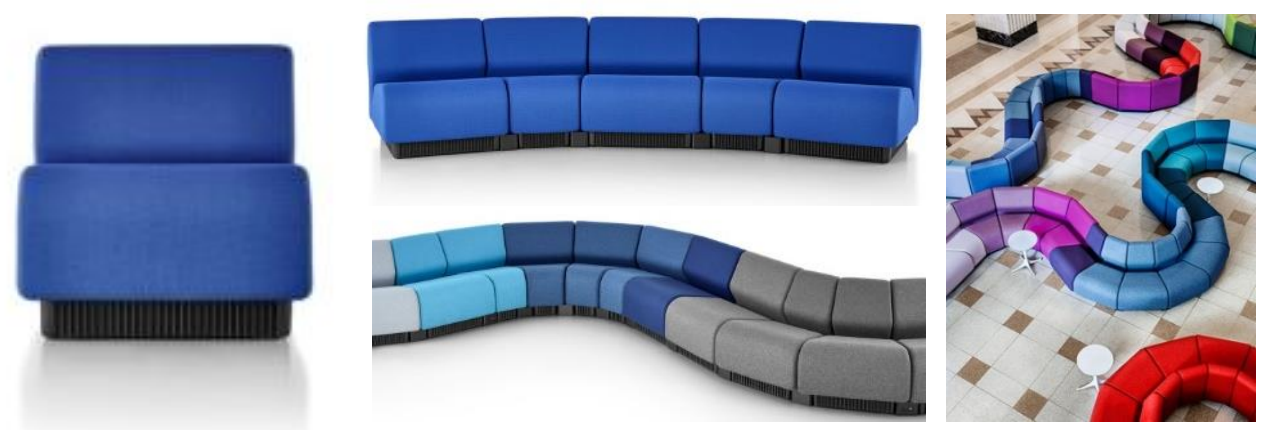

Şekil 11. Don Chadwick, Modular Seating, 1974 (Url-11)

Temel modül, görüntünün ana birimi olan pikselden ilham alınarak tasarlanmıştır. Farklı yüksekliklerde, kare zemine sahip yumuşak dikdörtgen prizmalar bir araya getirilerek özgürce yeni şekiller oluşturmaya imkân sağlamakta ve modülerliği sayesinde sonsuz sayıda şekil ve kompozisyonu mümkün kılmaktadır. Görünüşte basit olan her bir eleman yapısal olarak karmaşıktır. Tabanda daha sert fakat konfor sağlamak için üst kısımları daha yumuşaktır. Polipropilenden oluşturulmuş kontrplak bir tabandan oluşturulmuştur. Her bir modül ahşap kalıp çerçeve içine enjekte edilen alev geciktirici poliüreten köpük ve polyester elyaftan oluşturulmuştur. Her bir Do-LoRez modülünün kaplaması sökülebilir özelliktedir. Tasarımcısı Ron Arad çeşitli renk ve kumaş kompozisyonu sunmaktadır. Ama özellikle yün veya keçe kılıfları önermektedir.(Şekil 12).
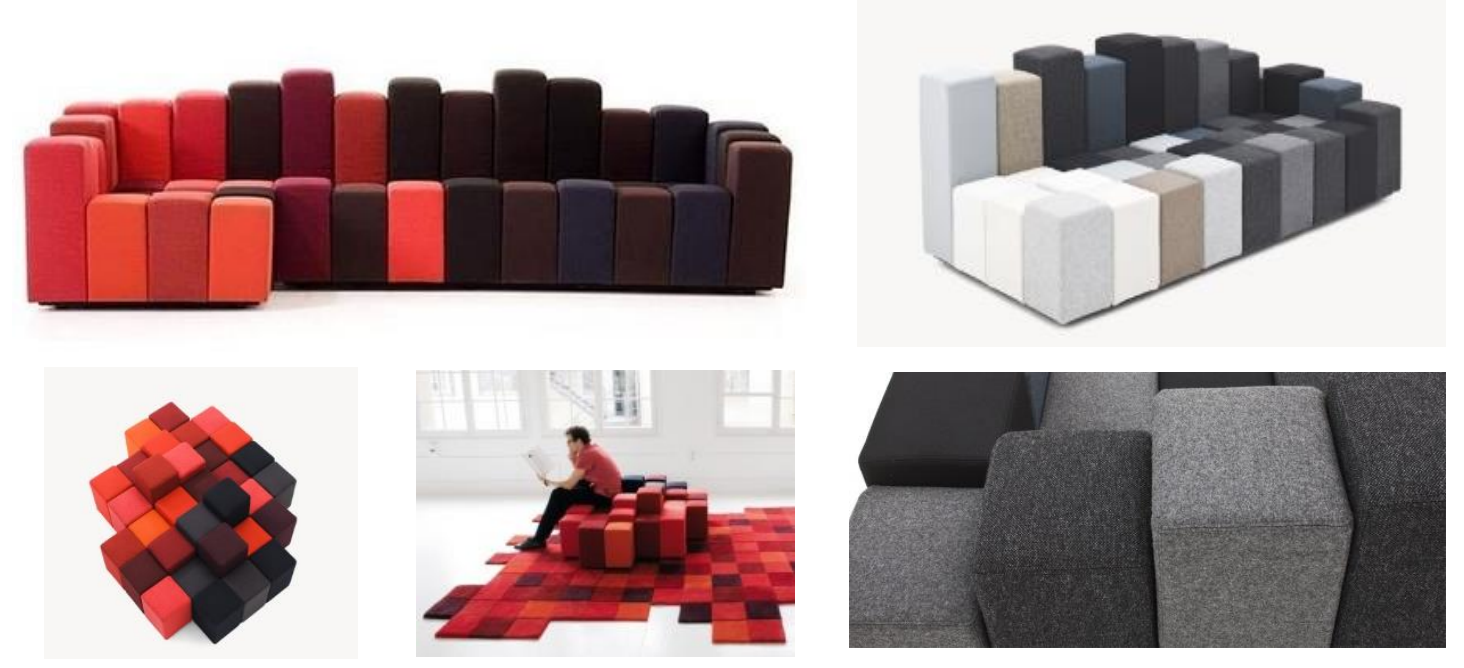

Şekil 12. Ron Arad, Do-Lo-Rez Sofa, 2008 (Url-12) (Url-13)

\section{Sonuç}

Tarihsel süreç içinde mobilya tasarım ve üretim süreci birçok aşamadan geçmiştir. Endüstri devrimiyle beraber seri ve bant üretim sistemleri ve makineleşme mobilyaların üretim sürecinde de yerini almıştır. Üretim yöntemlerine uygun; malzemeler geliştirilmiş ve yeni tasarımlar oluşturulmuştur. Emek yoğun üretimlerin kalitesi elde edilmeye çalışılmıştır.

Seri, bant üretim, yeni tasarım sistemi modüler tasarımı ortaya çıkartmıştır. Bu noktada dikkat edilmesi gereken husus modüler olarak seri bant sistemiyle üretilen mobilyaların tamamı modüler mobilya değildir. Sadece üretim yöntemi modüler olarak seri bant üretimde yapılmıştır. Modüler mobilya denilebilmesi için mobilyanın tasarım prensibinin de modüler olarak kurgulanması gereklidir.

Seri, bant üretim yöntemi ile modüler olarak üretilen modüler mobilyalar, geçmişin el işçiliği ile üretilen ağır mobilyalarının yerine kullanıcılara günlük yaşamlarında kullanım esnekliği sağlayan, standart, hafif, pratik ve ucuz mobilya sistemleri sunmuştur. Kullanıcı ihtiyaçlarını karşılamak için yerine özel tekil mobilyalar seçme yoluna gittiğinde özgünlük, rahatlık ve keyif gibi iyi hisler yaşamaktadır. Ancak her duruma özel çözüm aramak yorucu bir süreç olmaya başladığında standart hale getirilmiş modüler takım çözümler tercih görmeye başlamaktadır.

Tasarım ve kullanım süreçleri bakımından modüler sistemler birbirine zıt iki unsura neden olmaktadır. Bu standartlık durumu kazanımları bakımından oldukça verimlidir ancak belirli bir süre sonrasında sıkıcılığa neden olmaktadır. Bu durum kullanıcıyı ve tasarımcıyı mevcut ürünü geliştirme açısından kamçılamaktadır. Tasarımcı çok daha farklı kombinasyonların üretilebileceği tasarımlar 
ortaya koymaya çalışırken kullanıcı da mevcut ürünü üzerinde renk ve düzenleme değişiklikleri yaparak farklılık oluşturmaya çalışmaktadır. Kullanıcı bu sayede kullandığı ürün ile daha yakın bir bağ içine girmekte ve benimsemektedir.

Sonuç olarak; seri, bant üretim yöntemi kullanılarak standart parçaların bir araya getirilmesi ile oluşturulan (modüler üretim) mobilyalar, tasarımcı, üretici ve kullanıcı açısından avantajlar yaratmaktadır.

Modüler mobilya sistemlerinin avantajları şunlardır;

- Kullanım ihtiyaçlarının kişiden kişiye değişkenlik göstermesi veya aynı kullanıcının ihtiyaçlarının zaman içerisinde değişimine cevap verebilmesi

- Kullanıcıdan kullanıcıya değişen ölçü ihtiyaçlarını karşılama

- Farklı kişisel beğenilere cevap verme

- Kısa sürede çok sayıda üretim yapabilme

- İmalat ve üretim açısından ekonomik olma

- Çeşitli bütçelere uygun olma

- İmalat ve montaj kolaylığ 1

- Paketleme / Nakliyat kolaylığı

- Kullanıcının tasarım ve montaj sürecine katılması. (satış- pazarlama stratejisi)

- Standart ürün ortaya koyma.

\section{Kaynakça}

Berkin, G., Özcan, U., (2017), “Oturmanın Ergonomisi”, Yapı Dergisi (ISSN: 1300-3437, DAAI-Design and Applied Arts Index), Sayı: 426, s:140.

Boyla, O., 2016. Mobilya Tarihi. http://www.youblisher.com/p/589306-Mobilya-Tarihi-ekitaplarim-tr-gg/ (E.T.: 04.04.2016)

Eroyan, A., 2012. Thonet Yurtdışında İlk Kez Koleksiyon Tarafindan Üretilecek, http://www.mimarizm.com/haberler/thonetyurtdisinda-ilk-kez-koleksiyon-tarafindan-uretilecek 117243?PageNo=3 (E.T.: 17.05.2020)

Fiell, C. ve Fiell, P., 2011. Industrial Design A-Z, Taschen, 576, Köln.

Hadi, İ., 2013. İmre Hadi’ye ait (Güz yarıyıl1) Mobilya ve Mekansal Donanım Tasarımı Ders Notları (İstanbul Ticaret Üniversitesi) (80 sayfa) İstanbul.

Hasol ,D., 2010. Ansiklopedik Mimarlık Sözlüğü, 11.Baskı, Yem Yayın, 330, İstanbul.

Kayacan, B., 2017. Montajı Kullanıcı Tarafından Yapılan Mobilyaların Bir Kavram Olarak Değerlendirilmesi, İstanbul Ticaret Üniversitesi, Fen Bilimleri Enstitüsü, Yüksek Lisans Tezi, 66, İstanbul.

McGovern, S. M. ve Gupta, S. M., 2011. The Disassembly Line Balancing and Modeling, Mc Graw Hill, 373.

Müller, W. ve Vogel, G., 2012. Mimarlık Atlası, 1. Cilt, 1.Bask1, Yem Yayın, 17, İstanbul.

Özcan, U., Ürük, Z. F, "Modern Mimarlıkta Le Corbusier Etkisi ve Villa Savoye Mutfağı”, International Journal of Social and Humanities Sciences, sayı:3(1), Temmuz 2019, ss. 57-68, ISSN NO: 2602-3288

Özcan, U., Güngör, S.,(2019), "Yersizleşmeye Rağmen / Tadao Ando’yu "Yer" Bağlamında Okumak", Yapı Dergisi (ISSN: 1300-3437, DAAI-Design and Applied Arts Index), Say1: 453, s:42.

Özcan, U., Dağdeviren, Z.S.,(2019), "The Revitalization Of Urban Ruined Regions By Sustainable Design Thought Bronx / NY Sample", İçinde: Kaya, Latif Gürkan (Ed.), 2019, Research \& Reviews in Architecture, Planning and Design - Summer, 2019 (ISBN: 978-605-7852-92-2), Gece Kitaplığı Yayınevi, İstanbul.

Özcan, U., Güngör, S.,(2019), " Geleneksel Türk Evi ve Yapısal Özellikleri", İçinde: Kaya, Latif Gürkan (Ed.), 2019, Mimarlık, Planlama ve Tasarım Alanında Araştırma ve Değerlendirmeler - 2019 Haziran (ISBN: 978-605-7852-93-9), Gece Kitaplığı Yayınevi, İstanbul.

Özcan, U., Güngör, S.,(2019), "Geleneksel Türk Evi ile Geleneksel Japon Evi'nin Yapısal Açıdan Karşılaştırılması", Avrupa Bilim ve Teknoloji Dergisi (ISSN: 2148-2683, ULAKBIM TR Dizin ), Sayı:16, s:646.

Özcan, U., Erol, İ.,(2018), " Bir Ulaşım Kültürü - Metro Müzesi", Yapı Dergisi (ISSN: 1300-3437, DAAI-Design and Applied Arts Index), Say1: 440, s:58

Özel, Y., Ürük, Z.F, "Use of Plastic Materials in Furniture Design and Production", International Journal of International Journal of Advanced Research and Review, Y11:4, sayı:1, Ocak 2019, ss. 1-13, ISSN NO: 2455-7277

Schneiderman, D., 2011. Furniture as Prefabricator, Design Principles And Practices, An International Journal, vol:4,no:6

Saydan, R., 2004. 1900'lerin İlk Yıllarında Ford - General Motors Rekabeti (Üretim ve Pazarlama Anlayışının Karşılaştırılması), Balıkesir Üniversitesi Sosyal Bilimler Enstitüsü Dergisi, Cilt 7 Sayı 11, 153-159.

Ürük, Z. F, Öztürk, T. “Huzurevlerinde Yatak Odası Mekanının Gelişim Süreci, İstanbul ve Brüksel Örneği”, Avrupa Bilim ve Teknoloji Dergisi, say1:16, Ağustos 2019, ss. 662-678, ISSN NO: 2148-2683, DOI : 10.31590/ejosat.593611

Ürük, Z. F, Yılmaz, D., Boran, S “Özel Kurumlara ait Huzurevlerinin Mekansal Risklerini Fine- Kinney Yöntemi kullanarak İncelenmesi, İstanbul örneği”, İstanbul Gelişim Üniversitesi, Sosyal Bilimler Dergisi- Journal of Social Science, cilt:6, sayı:1, Nisan 2019, ss. 102-119, ISSN NO: 2148-4287, DOI : 10.17336/ igusbd.455165

Ürük, Z.F, "Medeniyetler İçinde Hamamın Gelişimi ve Kültürel Olarak Mekân Analizleri”, Akademik Sosyal Araştırmalar Dergisi- The Journal of Academic Social Science, Y11: 4, say1: 28, Temmuz 2016, ss. 185-209 Doi Number: http://dx.doi.org/10.16992/ASOS.1239

Url-1: http://arsenalofvenice.weebly.com/from-craft-production-to-industrial-production.html (E.T.: 29.12.2016)

Url-2: https://media.timetoast.com/timelines/industrial-design-history (E.T.:18.05.2020)

Url-3: https://www.diezoffice.com/stories/kitt-for-hay/ (E.T.:18.05.2020)

Url-4: https://www.dezeen.com/2010/03/30/offset-by-giorgio-biscaro-design-studio/(E.T.:18.05.2020) 
Url-5: https://www.hermanmiller.com/products/workspaces/desks/eames-desks-and-storage-units/(E.T.:07.01.2016)

Url-6: https://www.architonic.com/en/product/vitra-marshmallow-sofa/1003364(E.T.:18.05.2020)

Url-7: https://www.vitra.com/en-un/product/marshmallow-sofa(E.T.:18.05.2020)

Url-8: https://www.beoworld.org/prod_details.asp?pid=1174 (E.T.:18.05.2020)

Url-9: https://shop.noguchi.org/products/noguchi-black-prismatic-table? pos $=2 \&$ sid=a60ffa524\& ss=r $($ E.T.:18.05.2020)

Url-10: https://www.vertigohome.us/products/vitra-white-prismatic-table-by-isamu-noguchi (E.T.:18.05.2020)

Url-11: https://www.hermanmiller.com/products/seating/lounge-seating/chadwick-modular-seating/(E.T.:17.05.2020)

Url-12: https://moroso.it/prodotti/do-lo-rez-divani/?lang=en (E.T.:18.05.2020)

Url-13: http://homeklondike.site/2017/03/23/do-lo-rez-hand-tufted-3d-rug-from-100-new-zealand-wool/(E.T.:18.05.2020) 